\title{
Flood Management, Flood Forecasting and Warning System
}

\author{
Ehsan Hajibabaei \\ Department of Technical \\ and Engineering, Science \\ and Research Branch, \\ Islamic Azad University \\ Tehran, Iran
}

\author{
Alireza Ghasemi \\ Department of Technical \\ and Engineering, Science \\ and Research Branch, \\ Islamic Azad University \\ Tehran, Iran
}

\begin{abstract}
Flood phenomenon annually causes many human and financial losses so that flood has even had many losses in countries which are properly developed in river bank protection and construction of reservoir dams aiming to control flood. Today, controlling flood through its management is discussed and one of efficient and effective tools in this field is non-structural flood management as the complementary of structural ones that can have a very important role in controlling flood and consequently reducing the losses derived by that. Flood forecasting and warning systems are considered as one of the non-structural management tools which has given high importance within recent decades and providing information about flood and fast and easy reaction after receiving mentioned information to have minimum losses in flood areas as well as providing some information to manage water resources are of the aims of this system.
\end{abstract}

Keywords: controlling flood, flood forecasting and warning, flood non-structural management

\section{INTRODUCTION}

The relevant problems to the flood are various and have very complicated nature. In spite of all efforts all along history to inhibit and reduce flood damages through physical methods by people or governments, no country has been able to keep its flood areas completely safe regardless having assets and technology development. Due to this in some recent decades, non-structural strategies of flood management have drawn the attentions to moderate the losses of flood.

One of effective and efficient methods in non-structural flood management is providing and implementing a forecasting and warning system in catchment area that has been considered these days as an effective component on comprehensive management of flood and form a part of flood management of areas. Forecasting flood before its occurrence and warning the residents along rivers as well as authorities and responsible organizations in flood management give an opportunity to make decision about taking necessary measures such as planning for evacuation and displacement of people from dangerous areas, dams' reservoirs management and setting floods in dams as well as providing aid programs and doing other emergency measures in crisis. Identification and predicting of flood, warning and informing about the danger of flood, the program of necessary reaction in crisis, retrieval program after flood as well as interconnected management of system are considered as some sections of a flood warning system that among them predicting flood is one of the most important and meanwhile most complicated one and it is also regraded as important factor in the rate of system success.

\section{FLOOD MNAGEMENT STRATEGIES}

Flood management refers to the processes in inhibiting flood which moderate expansion of flood and the losses derived by that. Today considering the number of occurred floods in the world and the damages finically and life losses, its importance and inhibiting it have been more clarified. The related statistics to the damages of occurred floods and great expense which controlling the floods imposes on governments show that controlling all these floods is impossible and its losses can only be minimized through taking proper management strategies (structured and non-structured) [1]. Hamedi et al. proposed a structured method to minimize the flood effect to downstream of the dam properties by inclined the steps on the stepped chutes [2]. The effect of end sill to reduce the energy dissipation of the stepped spillways and protect the downstream of the dam from flood is also considered by Hamedi et al. [3]. They reported that using this structured method will reduce the flood destructive energy and will protect the downstream [3].

Shifting the attitude about flood management from structural methods to non-structural ones can be seen in recent years and this kind of attitude is a part of sustainable development principles. That is when a system of flood protection is established or modified to provide our needs, the principle of sustainable development commits us to be careful about future generations and their needs and consider that future generation might have other information which is unknown to us and because of that the solutions of flood management shouldn't be only as non-moving giant concrete structures or the ones which constantly break down [4].

Key point about different non-structural solutions is their synergic potential because effective function of these methods is the result of using them concurrently. Reaction measures without planning will obviously lack the necessary efficiency. Due to this, optimum synergy of non-structural and structural methods needs particular attention. Generally, of the reasons for the importance of completing structural methods using non-structural methods, the following cases can be mentioned [5]:

Lack of complete certainty about the performance of structures considering existing uncertainties as well as implementation shortcomings

- Creating severe changes in hydro systems because of human activities human activities in recent decades and increasing slow process of natural changes in terms of this 
- Better matching non-structural methods with technological advance that can be a tool for coping the harmful effects of hydro systems changes and using their supplies

- Applying non-structural methods is the only possible item while structure is constructed. This period can be long in very big plans and economically, reducing damages in initial years is more important than later years. Increasing the period of flood returning, designing and increasing the dimensions of structure in long-term can make the dangers of flood double because destruction of giant structures will usually have much disastrous consequent compared to when there is no structure at all.

- In many cases, restricting river path will bring undesired environmental consequences. Due to this, minimizing the dimensions of structures using combining structural and non-structural methods is desired.

- One fundamental principle in river engineering is gradual modification of river considering the response of river and mainly using the energy of flow that is aligned to fast construction of flood management structures. Non-structural methods can make more compliance between river engineering and flood management through reducing the dimensions of structures.

- In many cases non-structural methods are the only possible items such as warning and evacuating people in giant waves caused by tsunami in the shores or sea storms or breaking the dams

- Creating better recognition of hydro systems and its changes using non0structural methods and the possibility of better leading and compliance [5].

\section{FLOOD WARNING AND FORECASTING SYSTEMS}

Reducing the losses caused by flood using non-structural methods is a modern approach in flood management and flood warning system is one of them that has been used in some of countries in the world [6].

The importance of using these systems will be clear when using them in Bangladesh has caused 99\% reduction of human losses in 1997 compared to 1991 so warning flood is discussed as one of the most effective non-structural methods of flood management in order to manage crisis and reduce human and financial losses [7].

As one of flood management methods through predicting the time, severity and volume of fluid in catchment area, flood warning systems have significant role in reducing the damages of flood one hand and applying proper scenarios of exploiting water supplies of catchment area on the other hand [8].

One of motives for creating flood warning systems of rivers is reducing the damages of flood through warning the residents of flood areas and determining the real time exploitation of constructed dams on the rivers. Taking emergency actions and providing progressed information about flood is the initial aim of this system so that after receiving this information, it can be easily and quickly reacted. The second important aim of flood warning system is providing some information for managing water supplies. Therefore, the information of flood warning systems can be used for daily making decisions in allocating water supplies. Initial aims of flood warning system include:

- Reducing damages to people's life and property cause by flood

\section{Reducing disorder in business and human activities}

For achieving high goals, the measures below should be taken:

Improving and maintaining an effective communicational system between organizations and people

- Public participation and planning fast reaction to the danger

- Public training to react against flood according to predicting and warning sudden floods

- Making floodplain more effective and better

- $\quad$ Minimizing the time of reaction after broadcasting sudden flood [9]

In most of developed flood warning systems, forecasting system of flood acts smartly, in monitoring system, climate conditions are assessed in real time and continuously. By activating flood forecasting model, flood hydrograph is predicted in the points of goals. The results of forecasting will be given to crisis management organization and they make decisions about warning and informing people. General structure and schematic design of flood warning system has been proposed in figure 1 .

Conducted researches all around the world show different flood warning systems in different countries. This indicates that depending on the conditions of catchment, its hydrologic complication and different methods and goals, the system can have different efficiencies [5]. A flood warning system consists of different sub systems such as flood forecasting and identification sub system, flood warning sub system and emergency reaction sub system.

\section{PREDICTING PRECIPITATION AND FLOOD}

Hydrologic forecasting is estimating future status of a hydrologic phenomenon and the value of a forecasting depends on its accuracy to the great extent; required accuracy should be also proper with required function. Of the uncertainty factors in hydrologic forecasting, measurement errors, model restrictions and natural changeability of climate input to hydrologic systems can be mentioned [5].

In terms of dimensions and the speed of occurrence, the floods are divided into two categories of flash and river floods. Flash floods occur within a short time after raining (one or some hours) and happen in small steep basin. In terms of occurrence factors, these floods are complicated and due to effectiveness, they also cause many human and financial losses. Two factors of precipitation intensity and regional hydrology are important in the harsh floods. Flood forecasting and warning is very complicated and difficult due to low time between starting precipitation and the occurrence of flood and time is a restricting factor. The best mode of warning in this type of flood is estimating quantitative precipitation forecasting (QPF) through the meteorological methods and then the dimensions of flood are forecasted using precipitation-runoff models. But such facilities and data in small catchments aren't available [10] and [11]. Therefore, 
flood warning system in these catchments include forecasting or collecting precipitation data before or while precipitation as well as a model which can estimate flood and runoff caused by that.

In river floods that often occur along main rivers and in big areas, the effect of flood routing in reservoirs and dams as well as floodplains is considerable. In this mode, time isn't restricting factors in forecasting and can take several hours or several days. So in addition to the severity of precipitation and watershed hydrology (the factors such as physical characteristics and ...), watershed and river hydraulic and

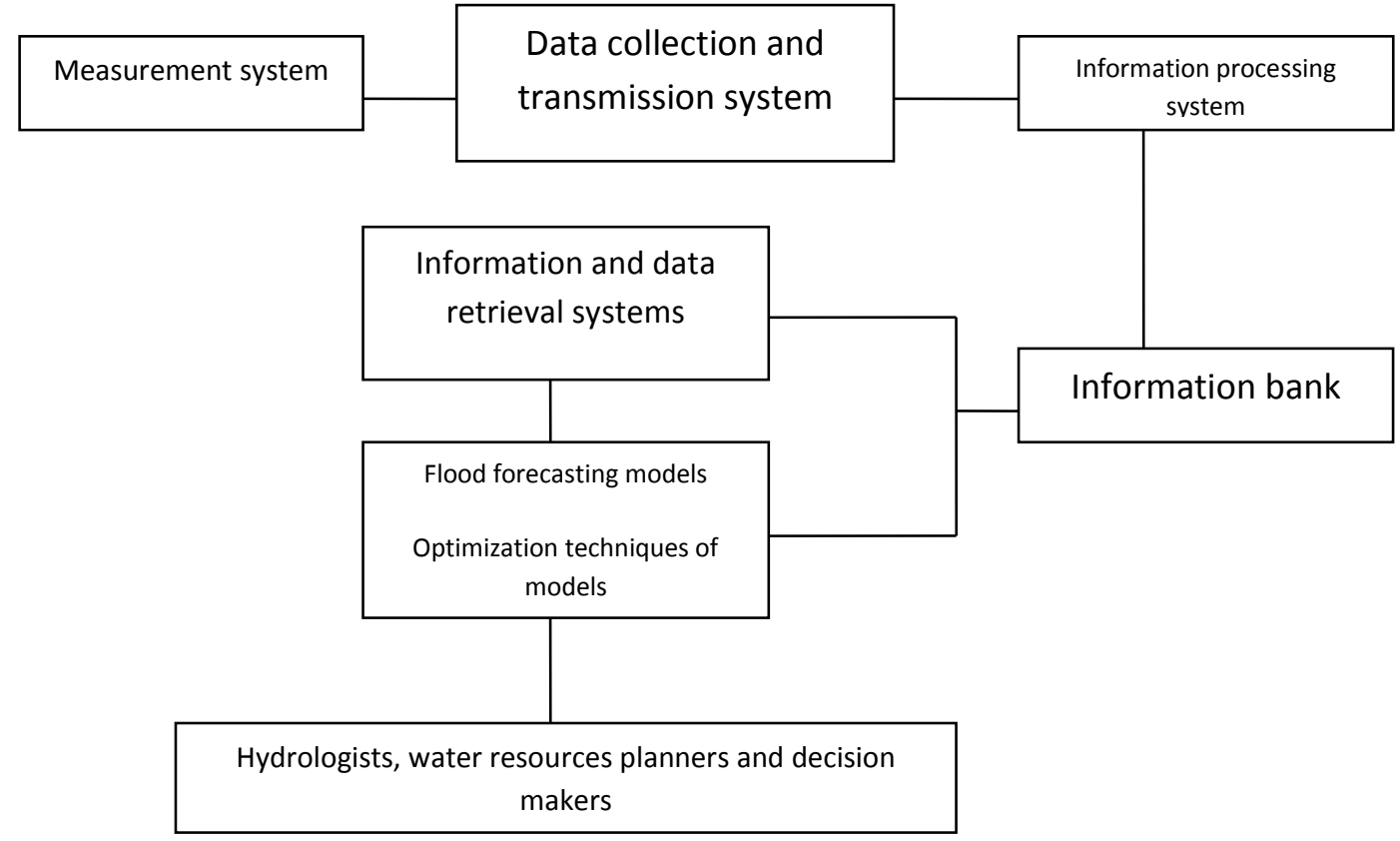

Figure 1. general structure of flood warning [12]

physical process of flow such as filling and emptying the tanks, water deviation from channels, dams and ... are also effective on flood problem. Flood warning technique in these catchments include forecasting precipitation before or collecting that in real time, converting forecasted precipitation or observation to flood, flood routing in river and reservoirs using one of hydraulic or regression methods and estimating flood in target points, following that, necessary information will be given [13].

Regardless the type and dimensions of flood, the following measures should be taken in predicting flood in a flood warning system [14] and [15].

- Providing precipitation-runoff model and hydrograph of flood created by forecasted and observed precipitation

- Routing forecasted flood in different points and determining the aspects and size of flood

Precipitation forecasting is one of the most difficult phenomena of hydrologic cycle because of high changes in time and location scale [10] and [16]. Forecasting precipitation is expected in different scales of high short time (up to 12 hours), short time (12 hours to 4 days), middle time (4 days up to one month) and ling time (seasonal, annual and climate periods). Precipitation forecasts used to be done through synoptic methods in the past in which forecasting was qualitative and in big scale based on experience. Today, along technologic progresses and using systems and tools such as satellite, radar and supercomputers and also using experts' experiences, significant developments have been achieved in perceiving and analyzing atmosphere phenomena, exchanges and atmosphere cycles and as result forecasting precipitations especially quantitative and numerical precipitations during different time periods.

Short term precipitation has an important role in time interval of 0-6 hours or maximum daily in flood warning. In flood warning system forecasting QPF very short time or generally short time in the scale of a catchment is required. Using QPF in forecasting the flow of rivers lets the time of forecasting and the efficiency of forecasting and warning flood to be increased [16]. Forecasting very short time precipitation about $0-6$ hours and with high transparency in place and time is often described as Nowcasting [17]. Dominant methods of forecasting short time QPF involve some factors such as numerical weather prediction models, observation based methods and numerical predictions (Blended system).

Among the methods above, numerical weather prediction (NWP) proposes the amount of precipitation quantitatively after doing post-processing operations and a specific time. Some models such as ARPS, ECMWF, MRF, WRF, MM5 and ETA are some kinds of mentions models. In terms of scale, these models are divided into two categories of global and regional categories. In terms of time scale as well as grid size the prediction is different.

The results of QPF of numerical prediction models are in the scale of big catchments and with high time step and practically the hydrologists can use a part of these information because for warning flood in small catchments or flash floods, they need QPF with high spatial resolution in the levels of 100 square kilometers and less and time step of one hour, 
therefore, using numerical models without localization is restricted due to some reasons such as restriction in minimizing the networks (e.g. up to $5 * 5 \mathrm{~km}$ ) and restriction in reducing forecasting time step.

To use the results of this model in small catchments, downscaling operations are conducted and through post processing measures (correcting output error of forecasting dynamic models for parameters of each level) the results of big scale numerical models will turn to integrated and shortterm precipitation in the catchment using regression models. In most of numerical models, neural networks as processing and also their calibration with ground rain-gauge data have been used and known as a strong tool in this field [10] and [18].

Today, executive agencies of America and Europe have used some methods of numerical methods that simulate precipitation less than 6 hours in bigger catchments than 1000 square $\mathrm{km}$ using integrated and contextual models [19] and [16].

\section{DIFFERENT TYPES OF FLOOD WARNING SYSTEMS}

Considering the type and technology capability which is used in its different parts in different levels of assessing base data, sending data, processing as well as how the flood is predicted, flood warning systems are divided into two general types of manual and automatic. Manual flood warning regional systems are of the least expensive and simplest systems and in primary type, using the services of volunteers and simple raingauge (plastic) and scale (rating level) in sensitive areas, they report their observations to coordinator of system while an automatic regional flood warning system consists of a network of different evaluators that report atmosphere and environmental conditions to a central computer.

An automatic flood warning system is usually able to act as a standalone system or in the form of a network and include some equipment such as fully automatic transmitter evaluators, a communication system and safe communication, automatic information collection and processor system and proper computer hardware. The components of an automatic regional flood warning system cannot be designed and implemented separately or without necessary coordination. This important issue is one of base requirements in equipping the area with automatic flood warning system [5].

Integrated and comprehensive flood warning systems are created through combining and integrating regional flood warning systems through making connection and interaction among them (exchanging two-way information) and are efficient in national or even international scale. This relationship is managed and coordinated from a country flood warning center by an equipped computer system [5].

\section{DECISION MAKING SUPPORT SYSTEM IN REAL TIME}

Decision making support system is a system consisting of software sub-systems and based on model and database and information that totally helps increasing the efficiency of decision makers in doing semi-structural responsibilities. Therefore, the first role of a decision making support system is helping the decision maker in the process of judgement and decision making about problems which haven't been defined well [20]. Mentioned system has different components and levels which work connected to each other and generally help managers to make decisions [21]. Champiri et al. had extensive researches to build decision and evaluation systems for marine structures which may be affected by different environmental hazards [20, 22].

Operationally, decision making support systems can be investigated in four levels of collecting data and information, existing solutions to solve problems, choosing the best item for solving problem as well as revising selected item in terms of implementation and relevance to the issue. The following cases are recommended for operationalizing a good decision making support system:

- Producing precipitation using meteorological models or through weather radar images

- Graphics of precipitation forecasts for probable accidents with big scale

- Simulation for predicting the hydrograph of water level balance in different points using hydraulic and hydrologic models

- Comparing all balances of water level related to time series with threshold water balances in order to analyze flood risk in time interval of prediction

- Determining peak balances of water level in prediction time period and at the times of reaching peak balances

- Providing graphical output display through connecting to graphical user of decision making support system as the layers of GIS map

- Providing relevant phrases to flood using initial format of flood phrase and creating code of HTML for public access to mentioned phrases using internet

- Analyzing investigated results in case of requiring warnings probable issuing to relevant authorities

- Transmitting predictions into standard databases system for documentation

- Issuing warning using available telecommunications and electronic tools

- $\quad$ Revising monitoring system to confirm the situation as well as be prepared for organizing activity [5]

\section{EMERGENCY REACTION SYSTEM}

The operation of reacting to flood can be managed through three methods below:

- Determining an organization for coping with flood: the operations are managed by operational leader of organization who act as flood operation manager.

- A general structure of emergency conditions management: operations are managed by a person in a particular control conditions with emergency management structure

\section{- A combination of two methods above}

According to global experiences, the management of emergency conditions of coping with unexpected events in the form of a national and integrated organization has had the best efficiency. Simply, flood is only one of precarious set of events that a developed nation should prepare the program for coping with. When they are located in a set of a multi- 
dimensional emergency coping comprehensive plan, emergency preparedness and coping with flood networks can take advantage of existing organizational systems and structures and through gathering the resources and experts in a complex, some measures can be taken to reduce the dangers of natural disasters such as storm, earthquake and flood and save organizational economy and cost.

In third mode that operation management is by a combination of mentioned cases above, the operations are managed by a person who is manager of flood operations, inside the structure of emergency management. The organizations of coping with flood are nominated for doing particular measures and they do them as the manager of emergency cases lead them generally. Choosing reaction management system significantly depends on general system of emergency management [5].

Emergency action plan (EAP) is an official document that follow a predesigned particular operation in order to minimize human and financial losses. This plan includes the methods and information to help a qualified person for releasing pre warnings and warning messages to the authorities of emergency cases management and to determine the actions which a qualified person should do in order to reduce relevant problems to the flood. Each emergency action plan should be provided for the location conditions considering all relevant features. Emergency action plans generally include 6 main components of warning diagram, discovering and classifying emergency situation, accountability, preparedness and flooded maps [5].

\section{REHABILITATION SYSTEM AFTER FLOOD}

Organizing implies on returning fundamental services to the performances before accident, helping people for selfsufficiency and self-confidence, repairing damages, giving financial facilities, rehabilitating economic activities and providing the fields of supporting the survivors mentally and socially while rebuilding include providing whole services and damaged infrastructures, replacing destructed buildings, rehabilitating economic activities and finally improving environmental conditions of affected community. During rehabilitating operation, some activities can be established to reduce the effects of future floods as follows:

Conducting studies and social surveys for exploiting the attitudes of flood management and its later consequences to acquire information related to replanning of strategies of people and assets and promoting the level of rehabilitation operation in future

- Conducting the studies of flood damages not only for determining the damages which have been occurred but also for avoiding the damages due to implementing the plans and individual and social activities

- Conducting the studies of economic effects in order to determine and localize the houses and states that get flooded frequently. These studies should be followed to the extent of turning a social responsibility

- Revising construction rules and land-use zoning to ensure constructions have been reinforced properly and also encouraging the owners for anti-flooding (keeping safe against floods) through reinforcing or other measures [5].

Also, considering that some components of flood warning and forecasting system are vulnerable against flood, probable damages on flood warning and forecasting system are necessary to be eliminated as soon as possible and the system need to be prepared for forecasting and warning likely later floods. Besides these methods, artificial intelligence and machine learning as a quick and powerful tool [23-25] can be used to predict and manage the flood. Bardestani et al. used ANFIS which is a combination of Neural Network and Fuzzy Logic in Water Resources [26].

\section{CONTINUES MANAGEMENT SYSTEM}

Reviewing and revising flood warning system, verification of forecasting models in a decision making support system, the programs and maneuvers of organizations for revising and reviewing the system, exploitation, planning and maintaining as well as developing flood warning comprehensive system can be considered as the goal of this system.

\section{CONCLUSION}

Using simple and applicable management methods especially for forecasting flood can be considered as the first step for developing flood management complicated systems and flood warning system is one of several non-structural methods which have been used to reduce flood. Forecasting flood before occurrence and warning the residents along rivers as well as authorities and responsible organizations in flood management give an opportunity to make decision about taking necessary measures such as planning for evacuation and displacement of people from dangerous areas, dams' reservoirs management and setting floods in dams as well as providing aid programs and doing other emergency measures in crisis and one of important aspect in this case is responsibility of different organizations involved in designing, developing, completing and exploiting flood warning system and in case there is no strategic organization, achieving this won't be easy.

\section{REFERENCES}

[1] Karamooz.M, (2008) "Runoff management based on risk analysis", $7^{\text {th }}$ international conference on river engineering, Ahvaz, Iran

[2] Hamedi, A., Ketabdar, M., Fesharaki, M., \& Mansoori, A. (2016). Nappe Flow Regime Energy Loss in Stepped Chutes Equipped with Reverse Inclined Steps: Experimental Development. Florida Civil Engineering Journal, 2, 28-37.

[3] Hamedi, A., Mansoori, A., Shamsai, A., \& Amirahmadian, S. 2014. The Effect of End Sill and Stepped Slope on Stepped Spillway Energy Dissipation. Journal of Water Sciences Research, $6: 1-15$.

[4] Shabanpour. F, (2011) "Management of runoff control based on risk and uncertainty analysis ", MSc dissertation, Tehran University, Tehran, Iran

[5] Mokhtare.A (2011), "A guidance on design, operation and maintenance studies of flood warning systems", deputy of planning and supervision, ministry of energy 
[6] Noroozi. A, (2006), "an investigation on the flood warning systems in Iran and comparison with similar systems in the world", $7^{\text {th }}$ international conference on river engineering, Ahvaz, Iran

[7] Mohamadi.H, Maghsoodi.M, Roshan.R, (2008) "The role of flood warning systems on decreasing the catastrophic effects of floods", journal of Geographic perspective, Vol.1, No.3

[8] Javaheri. N, Fatahi. E, (2011) "Introducing the flood warning sytem for Karoon river", $3^{\text {rd }}$ national conference on dams and power plants, Tehran, Iran

[9] Eslami. H, Zaker. M, (2005) "Karkhe river forecasting and warning flood system", $1^{\text {st }}$ international conference on crisis management, Tehran, Iran

[10] French, M., Harajewski, W. and Cuykendall, R., (1992), "Rainfall forecasting in Space and time using a network", journal of Hydrology, vol. 132, 1-31.

[11] Gupta, H., Sorooshian, S., Goa, S., IMAM, B., HSU, K. Bastidas, L., Lii, J. and MAHANI, S., (2002), "The challenge of prediction flash floods from thunder storm rainfall", Phil. Trans. R. Soc. Lond. 360, 1363-1371.

[12] Gholkhani.H, (2008) "Controling of flood and drainage engineering", p. 391, Tarbiat modares University publication, Tehran, Iran

[13] Shrestha, R., Theobald, S. and Nestman, F., (2005), "Simulation of flood flow in river system using artificial neural networks". Hydrology and earth system sciences, 9(4), 313-321.

[14] Mokhtare.A (2004), "Automatic local warning systems on floods", Mahab ghods consulting engineers, p. 191

[15] Luk, K., Ball, J. and Sharma, A., (2000), "A study of optimal model $\log$ and spatial input to artificial neural network for rainfall forecasting", journal of Hydrology, $227,56-65$.

[16] Vovoni, E., Entekhabi, D., Bras, R., Ivavov, V. and Horne, M., (2005), "Extending the predictability of hydrometeorological flood events using radar rainfall nowcasting", Journal of hydrometeorology, vol. 7, 660677.

[17] Rivolta, G., Marzano, F., Coppola, E. and Verdecchia, M., (2006), "Artificial neural network technique for precipitation nowcasting from satellite imagery", Advance in Geosciences, 7, 97-103.

[18] Yerong, F. and kitzmiller, S., (2006), "A short-range quantitative precipitation forecast algorithm using Backpropagation neural network approach", Advance in Atmospheric Sciences, vol. 23, No. 3, 405-411.

[19] Damrath, U., Doms, G., Fruhwald, D., Heise, E., Richter, B. and Steppeler, J., (2002), "Operation quantitative precipitation forecasting at the German weather service", Journal of Hydrology, 239, 260-285.

[20] Champiri, M. D., Mousavizadegan, S. H., Moodi, F., (2012), "A Decision Support System for Diagnosis of Distress Cause and Repair in Marine Concrete Structures", International journal of Computers and Concrete, Techno press, Vol. 9, No. 2, pp. 99-118.
[21] Ardestani, M, Nazarbaha. M, Omidvar. B, Emami. K, (2007) "configuration of flood warning system for Tehran ", 3rd international conference on crisis management, Tehran, Iran

[22] Champiri, M. D., Sajjadi, Shahin, Mousavizadegan, S. H., Moodi, F., (2016) "Assessing of Distress Cause and Estimating Evaluation Index for Marine Concrete Structures, American Journal of Civil Engineering and Architecture, Science and Education Publishing, 4(4), 142-152.

[23] S. Sajjadi, S. Shamshirband, M. Alizamir, L. Yee, Z. Mansor, A.A. Manaf, et al., Extreme learning machine for prediction of heat load in district heating systems, Energy Build. 122 (2016) 222-227.

[24] Gandomi, A. H., Sajedi, S., Kiani, B., and Huang, Q. (2016), "Genetic programming for experimental big data mining: A case study on concrete creep formulation", Automation in Construction, 70, 89-97.

[25] Kiani, B., Gandomi, A. H., Sajedi, S., and Liang, R. Y. (2016), "New formulation of compressive strength of preformed-foam cellular concrete: an evolutionary approach", Journal of Materials in Civil Engineering, 28(10), 04016092.

[26] Bardestani, S., Givehchi, M., Younesi, E., Sajjadi, S., Shamshirband, S., \& Petkovic, D. 2016. "Predicting turbulent flow friction coefficient using ANFIS technique.” Signal, Image and Video Processing, 1-7. 